\title{
A HOLISTIC SOLUTION INTEGRATING MULTIPLE INTERPRETATION TECHNOLOGIES TO ENHANCE SUSTAINABILITY OF POORLY ACCESSIBLE WORLD CULTURAL HERITAGE: THE EXAMPLE OF HAILONGTUN
}

\author{
Wei Ren ${ }^{12}$, Yuanshuang Zhu ${ }^{3}$, Ming Du ${ }^{3}$, Jian Lai ${ }^{3 *}$ \\ ${ }^{1}$ Zhejiang University City College, Zhejiang, China - wei.ren1012@foxmail.com \\ ${ }^{2}$ College of Architecture and Urban Planning (CAUP) Tongji University, Shanghai, China - wei.ren1012@foxmail.com \\ ${ }^{3}$ Tongji Architectural Design (Group) Co., Ltd., Shanghai, China - 52lj@tjad.cn
}

KEY WORDS: Sustainability, poorly accessible, World, Cultural, Heritage, Hailongtun.

\begin{abstract}
:
Cultural Heritage sites with poor accessibility preventing tourists visiting, and there are few studies that specifically explore the practical problems and measures faced by poorly accessible world cultural heritage sites in terms of sustainable development. This research suggested a holistic solution that integrates six emerging technology methods and implements them with the case study Hailongtun Tusi, in Guizhou Province, China. This research provides a new idea for promoting sustainable development of world heritage based on 3D digital technology. Due to its simple technology and controllable cost, it also provides a model for other countries faced with similar issues in managing their world cultural heritage sites.
\end{abstract}

\section{RESEARCH BACKGROUND}

The Convention for the Protection of the World Cultural and Natural Heritage was adopted by the General Assembly of the United Nations Educational, Scientific and Cultural Organization (UNESCO) on November 16, 1972, and aims to protect the cultural and natural heritage of outstanding universal value worldwide. After being listed in the World Heritage List, cultural heritage sites gradually become popular tourist destinations. The flocking tourists then put pressure on the ultimate carrying capacity of the heritage site. Under the promotion of the United Nations 2030 Sustainable Development Goals (SDGs) and the current status of heritage tourism, the main challenge facing world cultural heritage has gradually changed from protection to determining how to promote sustainable tourism.

Not all world cultural heritage sites are overcrowded or face great tourism pressure, and the number of visitors to some sites is still very small. Poor accessibility is the main reason preventing tourists from visiting world cultural heritage sites. For example, the development of local society and the tourism industry around Hani terraces in Yunnan has been severely restricted due to inconvenient transportation. Inaccessibility as considered in this study is not limited to the disabled, but includes all tourists whose access is limited due to natural environmental factors. For example, some heritage sites are located in remote areas, including isolated islands, mountaintops, or in dangerous terrain, which causes poor accessibility.

Heritage sites with poor accessibility and those with good accessibility face different problems, and there are few studies that specifically explore the practical problems and measures faced by poorly accessible world cultural heritage sites in terms of sustainable development. Poor accessibility means that a site's outstanding universal value cannot be effectively transmitted to stakeholders, and it cannot play its intended role in heritage education and dissemination of world heritage. Heritage tourists are a mixed blessing: they pose a threat to the site, but they also promote its outstanding universal value by appreciating its value. Heritage tourism can also bring certain economic benefits to management units and local residents, and this income is an important economic resource for maintaining the survival of heritage residents. If the number of tourists in heritage sites is small, high investment from local governments in heritage tourism may help encourage local economic growth, creating a virtuous circle of development. The reverse is also true, and a vicious circle could appear if fewer tourists visit, which would lead to lower incomes, which in turn would lead to restrictions on economic development, resulting in less investment in heritage protection, use, and publicity, which would in turn limit the visibility of the world cultural heritage, so tourists would remain few in number, and finally, the site would be still further disadvantaged in the increasingly competitive heritage tourism market.

For world cultural heritage sites with poor accessibility, heritage protection and activation have been the focus of technological breakthroughs. Single technical means of heritage management have, however, tended to be limited in scope and focus on either heritage protection, or heritage interpretation and tourism promotion. This research therefore proposes a sustainable heritage development approach that integrates multiple digital methods, hoping to confront with flexibility the problems faced by different world heritage sites. The scientific problem is not how to use emerging interpretation technologies in heritage management, but how to take comprehensive technical measures to improve the interpretation and presentation effects despite poor accessibility for different sites. The crux of sustainable world heritage development is that stakeholders must interact and communicate to counteract poor accessibility.

This paper proposes a holistic solution that integrates multiple three-dimensional (3D) digital technologies and implements it with the case study Hailongtun Tusi, in Guizhou Province, China. A literature review and field investigation, involving interviews with different stakeholders, support the analysis of the main problems faced by the site, especially stakeholders' lack of awareness of outstanding universal values and the insufficient interpretation and presentation of world cultural heritage. Based on six emerging technology methods, we then propose solutions to the problems faced. This research provides a new idea for promoting sustainable development of world heritage based on 3D digital technology. Because of its simple technology and controllable cost, it also provides a model for other countries faced with similar problems in managing their world cultural heritage sites. 


\section{LITERATURE REVIEW}

Although there has been significant research on heritage sustainability in recent years (Cassar, 2009; Hribar, Bole, \& Pipan, 2015; Landorf, 2009), there is still a gap on how to define the dimensions of heritage sites. It has been the tradition for the dimensions for sustainability to be associated with the local economy, environment, and society. However, this definition may not suit a given heritage site, depending on its nature. The research scope on sustainability for heritage sites has been varied (Auclair \& Fairclough, 2015a; Caserta \& Russo, 2002; Leff, 2012; Li \& Hunter, 2015; Silberman, 2007; Throsby, 2009 ), while the research on heritage and sustainability has focused on varying topics, including theory and practice (Auclair \& Fairclough, 2015b), methodology for sustainable appraisal (Gullino, Beccaro, \& Larcher, 2015; Ren \& Han, 2018 Stubbs, 2004), the challenge of sustainability and cultural heritage (Barthel-Bouchier, 2016), heritage preservation and sustainability (Wai- Yin \& Shu- Yun, 2004), the sustainability of mining heritage tourism (Cole, 2004), and coastal zones (Howard \& Pinder, 2003). However, little research has really answered the question of what the dimensions of heritage sites are.

The definition of sustainability for heritage should be based on economic, social, environmental, and governance dimensions that consider the relevant sustainability indicators. That is, to achieve sustainability, this research argues that a heritage site should provide economic support for locals, ensure the integrity and authenticity of heritage site itself, and promote the outstanding universal value of heritage sites in general.

World heritage sites with limited accessibility face more challenges in achieving sustainability than normal sites. In the present study, the term "limited accessibility" refers to heritage sites that are difficult for visitors to reach because of the site's physical environment, such as those in rural areas or mountains. This topic has been the subject of quite a bit of research. (Partarakis et al., 2016), for example, aimed to address the accessibility of cultural resources by proposing a new approach for accessible user interaction, based on ambient digital intelligence and interaction techniques for enhancing accessibility. However, while this proposed suggestion might be very useful for cultural heritage sites with enough professional and economic support, for sites with limited accessibility in rural areas with a small budget, there may not be any professionals available to provide technological support. To achieve sustainability, therefore, low cost and easily operated technological support for such heritage sites must be developed.

An increasing number of emerging technologies are being employed in heritage sites (Kosmas et al., 2020; Neumüller, Reichinger, Rist, \& Kern, 2014; Paladini et al., 2019; Puyuelo Cazorla, Higón Calvet, Merino Sanjuan, \& Contero, 2013), and most of them support the sustainability of the heritage site. Three-dimensional printing technologies have been employed to promote cultural heritage preservation, accessibility, research, and education (Neumüller et al., 2014). (Paladini et al., 2019) have proposed an approach providing accessibility to knowledge and understanding using virtual reality (VR) using an inaccessible Buddhist temple in the Myanmar city of Bagan as a case study. (Parrinello \& Dell'Amico, 2019) have noted that preserving and enhancing cultural heritage requires reflection on databases as the containers for information about the accessibility of dispersed heritage. However, these approaches have not been related to each other, and world heritage sites with limited accessibility require an integrated approach that covers more actions to achieve sustainability, as an individual approach only can address single challenges. This study therefore attempts to address this research gap and to develop an integrated approach with more than one emerging technology that would help support heritage sites with limited accessibility in achieving sustainability.

\section{METHODOLOGY}

\subsection{Case study selection}

Hailongtun is a mountainous defensive castle built by the chieftain of the Yang family of Bozhou at the heart of his dominion. It was used with the Bozhou Xuanwei Suo (now Zunyi Old Town) on the plain on the west bank of the Xiangjiang River and was the administrative and military center of the Bozhou chieftain when at war. In July 2015, Hailongtun, as a component of Guizhou's series of Tusi Sites heritage, was included in the World Heritage List at the 39th World Heritage Conference held in Bonn, Germany. It has a shorter tourism development time and a smaller core heritage area than is common for a cultural heritage site in China. The specific reasons for choosing Hailongtun as the pilot are outlined below.

First, Hailongtun is a typical representative of poorly accessible world cultural heritage, as it is located at the top of Longyan Mountain, about 28 kilometers northwest of the old city of Zunyi, in Guizhou Province. It is surrounded by water on three sides and by a mountain on the other. The core heritage area is 160.42 hectares (Figure 1). The fortress mainly includes relics from the Wanli period of the Ming Dynasty (1595-1600), which are scattered on Longyan Mountain at a relative elevation difference of nearly 400 meters. Only the southeast sides have small paths (Figures 2-4). According to the "Hailongtun Conservation Management Plan (2013-2030)" and the relevant provisions of the World Heritage Convention, all construction projects in the Hailongtun Cultural Heritage Site are strictly restricted, especially in the core area, which thus basically retains its original features except for the addition of footpaths and toilets. Although Hailongtun has 5,838 meters of city walls, nine city gates, the site of the new palace, quarries, kiln sites, and Longhu Avenue, among other types of historical remains, few tourists visit the site due to poor accessibility.

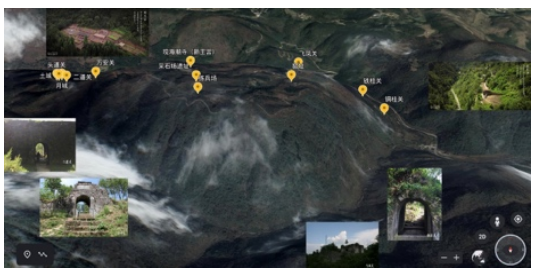

Figure 1. Aerial photography of Hailongtun.
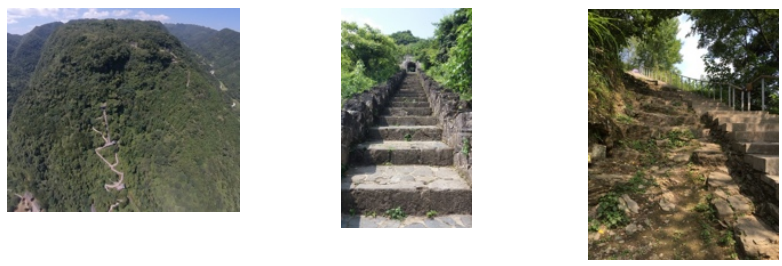
drone photography of the only uphill road to Hailongtun

Qianshan.
Figure 2. Aerial
Figure 3. Bottom left, the current remaining

Hailongtun uphill road.
Figure 4. Right, 36 steps of Hailongtun (one of the main military defenses). 
Second, it was also chosen based on the research foundation of multiple scientific research projects. In 2016, Hailongtun was selected as the pilot site of the World Heritage and Sustainable Tourism Project in China. The author team obtained much data during the implementation of the project. In 2018, Hailongtun successfully applied to be the first demonstration base for the integration of science, technology, culture, and tourism in the city of Zunyi, Guizhou Province, to empower the interpretation and presentation of Hailongtun's outstanding universal value. The management unit attaches great importance to broadcasting the site's cultural heritage values, and innovations in this area form the basis for the implementation for the current project in Hailongtun.

\subsection{Technical method}

Hailongtun must confront the problem of insufficient interpretation and presentation of its outstanding universal value, which is an important factor restricting its sustainable development. The present research therefore analyzes the relationship between world cultural heritage, sustainability, and new interpretation technologies from the perspective of raising stakeholder awareness of outstanding universal values based on emerging technologies, based on the premise that interpretation technologies are a logical pathway for promoting world cultural heritage and an important means of sustainable development. For world cultural heritage sites with poor accessibility, combined technical means may be more applicable than single technical means broadening the scope for presenting its outstanding universal value.

This study synthesized six technical methods for complementary use to make up for the shortcomings created by poor accessibility; these are 3D scanning and digital recording of the world heritage using drones, reverse restoration of a model based on 3D printing technology, construction of a panoramic presentation system for the site based on 3D panoramic technology, and digital restoration of damage to cultural relics based on digital carving technology as well as restoration of cultural relics based on 3D interpretation and presentation technology, and an aerial photography presentation system based on VR technology.

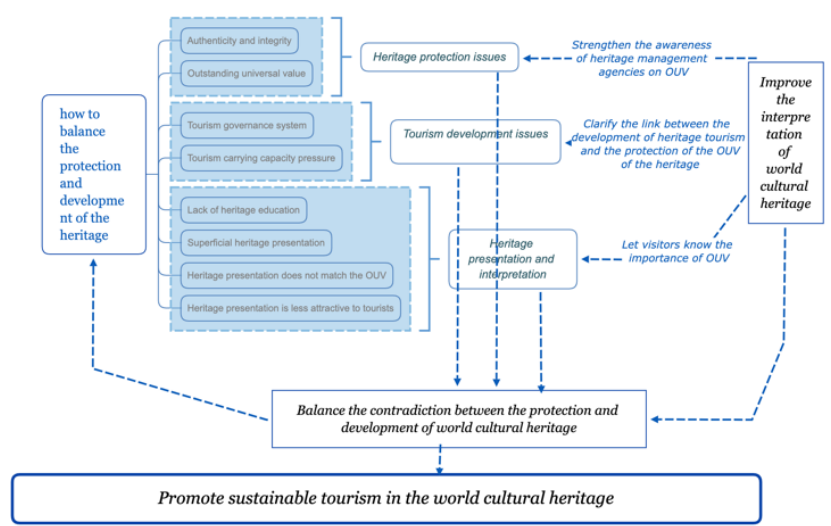

Figure 5. The logical relationship between sustainable tourism and interpretation based on emerging interpretation technologies.

\section{METHODOLOGY}

The UNESCO WHST (world heritage sustainable tourism) project has identified that the different stakeholders for the World Cultural Heritage Tusi Site of Hailongtun must face problems such as an inaccurate understanding of its outstanding universal value. One cause of this lack of understanding is its poor accessibility, but the inaccurate understanding is also a key factor restricting the site's sustainable development. This study therefore explores how to promote the interpretation of the site's outstanding universal value based on 3D visualization technology, thus enhancing stakeholder awareness of that value, and broadening the scope of research ideas about sustainability at Hailongtun.

\subsection{D digital recording with drones}

Protecting the authenticity and integrity of a site is not only the basic principle of heritage protection but also the foundation of sustainability. Poorly accessible, the heritage remains of Hailongtun Tusi are situated on a mountain, prone to geological disasters and natural environmental damage, which threatens the authenticity and integrity of the heritage site (Figures 6 and 7). The use of digital recording methods can accurately and completely record world cultural heritage, which is important considering that such sites may encounter critical moments in the future. Information about the heritage site can be more comprehensively restored based on digital records. These heritage information models serve as the basis of sustainable heritage tourism. This technology was therefore used to perform a 3D digital scan of Hailongtun and to build a model for public presentation (Figure 8).

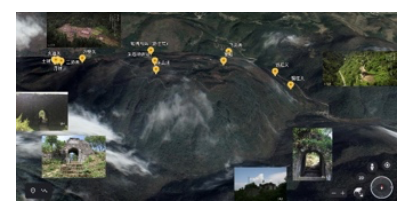

Figure 6. Topographic map of Longyan Mountain based on Google.

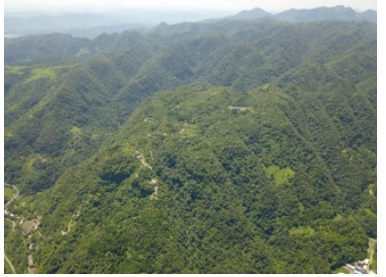

Figure 7. Aerial photograph of Longyan Mountain

Information about the heritage site can be more comprehensively restored based on digital records. These heritage information models serve as the basis of sustainable heritage tourism. This technology was therefore used to perform a 3D digital scan of Hailongtun and to build a model for public presentation (Figure 8).

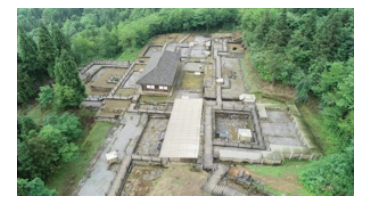

Figure 8. New Palace Site, Hailongtun.

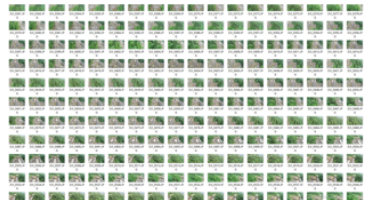

Figure 9. Photo collection for part of the New Palace, Hailongtun.

The creation of a 3D digital model of Hailongtun based on unmanned aerial vehicle (UAV, also called drones) photography was divided into the following three steps: (1) acquisition and processing of field data; (2) real-space 3D modeling; and (3) presentation of results and model digital twin application. 
4.1.1 Image data collection and processing of the main relics of Hailongtun: In the process of acquiring and processing field data,the accuracy of the collection and processing of photos or photographic images was key to determining the quality of the digital model. To ensure the quality of the results, the following steps were carried out:

(i) Geographic survey data. This involved sorting out and analyzing the geomorphology and planning the UAV aerial photography route in advance. The target landform and the surrounding environment of the building were surveyed, and a plan was made for the aerial photography flight (automatic or manual), trajectory route, and photography based on the project overview, such as the area occupied, the appearance of the features, location, height, and other attributes, and the surrounding meteorological environment. Equipment requirements were then considered. When shooting outdoors, cloudy weather is better than sunny, as this reduces the likelihood of high-contrast shadows, which can obscure details. A stable ambient light source is, however, a better choice than changeable natural light, which would increase the risk of overexposure and/or underexposure.

(ii) Adjust and determine the parameters for the UAV aerial photography. Before undertaking aerial photography, the parameters such as the degree of overlap, sensor, focal length, flight speed, and photo interval of the captured image data were adjusted. The UAV image capture lens should use a fixed focal length, and if a variable focal length lens is used, the same focal length must be used for all images; this was verified before photography commenced.

(iii) Observe changes in the surrounding environment at all times and carefully collect images vertically. During the UAV aerial photography acquisition process, image overlap was checked constantly. The overlap between images should exceed $60 \%$ while ensuring that the side overlap is not less than $70 \%$, and the heading overlap is not less than $80 \%$. Layering was also carried out, which involved shooting three distances from far to close, so that the middle layer was connected to the two other layers; the height was also layered. The main purpose of this was to restore the texture information for the reconstructed photo to the greatest extent. To better capture the real scenes of the building facades (such as Hailongtun's gates and the New Palace), vertical and oblique images were collected at the same time to ensure the collection of all regional data and to avoid model fracture problems caused by information leakage. When encountering a landform with a single surface texture, it was necessary to add one or two reference objects in the shooting range to clarify the relative position of each photo, which later helped in calculation and point cloud generation.

(iv) Organize the collected data and images, preview the collection results, and determine whether to go around. The scope and quantity of the collected images were divided according to the on-site targets; the images collected by drones and the images collected by external shooting were also classified. No editing was done before importing the original image into the data processing software; the raw files were not adjusted by changing the size, cropping, rotating, reducing noise, sharpening or adjusting brightness, contrast, saturation or hue, or any other of the standard minor image-processing modifications.

The data were collected in August 2019 for Hailongtun's nine gates, Old and New Palaces, kiln sites, and quarries. Because of
Hailongtun's complex terrain and landforms, five-way multiheading flights and high, medium, and low-altitude circling flights were used to collect data from the ground. Nearly 10,000 photos were collected throughout the entire process, with an average of 1,000 photos per scene. When a scene had been completely captured, the images were checked for deficiencies, and additional data were acquired as needed (Figure 9).

4.1.2 Hailongtun New Palace: A case study of real-life modeling: The real-scene model was created using ContextCaputure Center Master (formerly Smart3D) series software on the Bentley platform. The following steps were followed during the model creation process.

(i) Import heritage aerial photography data. After the photographs or videos from the image group were imported into the ContextCaputure software, the image group was checked for invalid or missing data. In the event such data were found, manual positioning of the point reference was performed. Once the data group repair was complete, we checked whether any photo data groups were missing, and, if so, group photo connection filtering and sorting or additional UAV image collection were performed. The $3 \mathrm{D}$ view section was then entered to check photograph positioning.

(ii) Aerotriangulation. The positioning mode was selected in the General section to prepare for Aerotriangulation processing. The Aerotriangulation calculation process starts when the ContextCaputure Engine software is opened. After the Aerotriangulation has been processed, the accuracy of the results is reported in the General Aerotriangulation plate, and the relative positions of the pictures and a schematic model of the $3 \mathrm{D}$ view area can be seen; clicking on the photograph allows a preview of the model's photo range.

(iii) Reconstruction and generation of digital heritage data. After the successful Aerotriangulation processing, the spatial framework section was used to generate the data group in blocks; the model generation range could also be set manually to speed up processing and increase cluster-processing efficiency. The model type and data format were selected, the texture compression ratio and node size were set, and then the reconstruction was submitted via the General section. In the Properties section, all the processing details for the model are shown with the completed model reconstruction.

(iv) 3D model preview and digital result output. Using the ContextCaputure Viewer software, the $3 \mathrm{MX}$ scene data for model preview were opened, and the result folder was then packaged, compressed, and uploaded to the cloud platform for model preview. The model results were exported in various data formats, so the digital results could be applied to other fields such as geographic information technology (Figure 10).

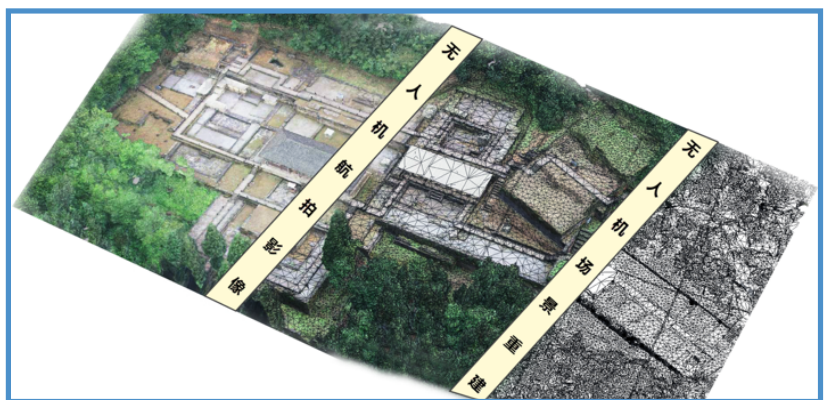


Figure 10. Comparison of drone aerial images and scene reconstruction.

\subsubsection{D presentation of digitalization results and model delivery:}

The project generated a set of $3 \mathrm{D}$ data models of the important relics from the Hailongtun World Cultural Heritage site, including the Thirty-Six Steps, Feihu Gate, Chaotian Gate, Feifeng Gate (Figure 11), Feilong Gate, Toudao Gate, Erdao Gate, Wan'an Gate, Tongzhu Gate, Tiezhu Gate, the New and Old Palaces (Figure 12), kiln sites, and quarries. The digital results were ready for application with various $3 \mathrm{D}$ digital information technologies.

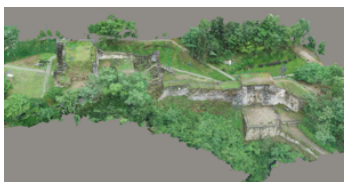

Figure 11. 3D digital model of Feifeng Gate.

Lightweight data processing was performed on the generated 3D digital model of Hailongtun. High-precision geographical $3 \mathrm{D}$ spatial data and true color texture information were collected, which can more objectively reflect the true status of immovable cultural relics. The captured data can support the simulation of restoration of the New Palace; digital duplication of unearthed cultural relics, cultural and creative products; reduction of the likelihood of force majeure damage caused by repeated exposure of the immovable cultural relics during tourism and research; and sharing of resources and data with WeChat QR codes (Figures 13-16). This contributes to archaeological research work at the site and better promotes its outstanding universal value as an example of world cultural heritage.

\begin{tabular}{|c|c|c|c|}
\hline 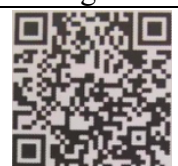 & 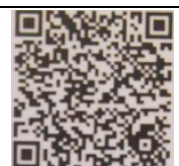 & 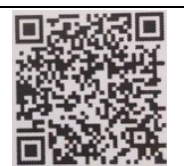 & 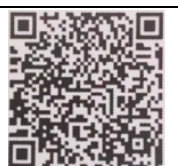 \\
\hline $\begin{array}{l}\text { Figure } 13 \\
\text { New Palace. }\end{array}$ & $\begin{array}{l}\text { Figure } 14 \\
\text { Wan'an Gate. }\end{array}$ & $\begin{array}{l}\text { Figure } \mathbf{1 5} . \\
\text { Copper post. }\end{array}$ & $\begin{array}{c}\text { Figure 16. } \\
\text { Chaotian } \\
\text { Gate and } \\
\text { Feifeng Gate }\end{array}$ \\
\hline
\end{tabular}

\subsection{D digital recording with drones}

Due to the poor accessibility of the roads leading to the main gateways of Hailongtun, it is difficult for tourists to visit the artifacts in situ, and the traditional flattening process of making a model with accurate proportions is very time consuming and labor intensive. Protection and restoration are also not conducive to the true and effective presentation of world cultural heritage. We therefore considered how to create a reverse restoration of the main gates based on $3 \mathrm{D}$ printing technology, and this may be one of the most important attempts to promote sustainable development with heritage protection of the site.

The basic information for the 3D model involved first obtaining high-precision $3 \mathrm{D}$ point cloud data from the multi-angle UAV aerial photography. The data already collected during the preliminary research for the construction of the 3D model was also used here (Figure 17). The Erdao Gate, Hailongtun, is here taken as a case study for restoration based on 3D printing, which can accurately depict the appearance of the Hailongtun site; the digitization can be easily stored, edited, and shared around the world, broadening the scope of the effective presentation and promotion of the heritage site's outstanding universal value.

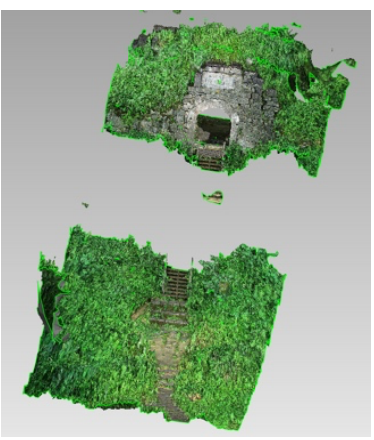

Figure 17. Completed 3D data for Erdao Gate,

Hailongtun, based on point cloud information.

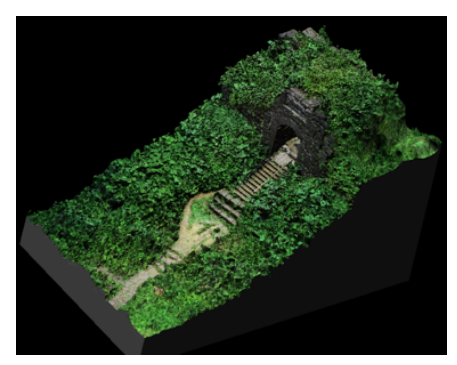

Figure 18. Point cloud data for Erdao Gate, Hailongtun, after restoration.
The volume of 3D data constructed using drones was huge, however, and is not suitable for direct $3 \mathrm{D}$ printing. Lightweight processing was required. The team first edited the point cloud data (i.e., deletion, sampling, and noise reduction) and then the mesh (i.e., deletion, hole filling, trimming, and repair). Point cloud data usable for $3 \mathrm{D}$ printing was obtained via this process (Figure 18).

The team combined this $3 \mathrm{D}$ data with the existing, relatively mature, color powder bonding technology to perform 3D print processing. Color powder bonding printing prints quickly, requires no support structure, and can output color products. The specific procedures included using powdered materials, pushing the composite powder through the roller to the modeling platform, and spraying the adhesive through the nozzle. The cross-sections of the workpiece were stacked layer by layer, and then the colored adhesive was "printed" on the powder to complete the full-color printing (Figures 19 and 20).

If the Hailongtun relics are printed with a colorless white mold, the resulting presentation effect is poor, so the color powder bonding technology was used. The 3D printed World Heritage Gate was an attempt to presentation the remains of the Hailongtun site to allow more tourists to encounter a model of this world heritage site (Figure 20). Hailongtun digital replicas can be customized via dimension printing according to the needs of different audiences in different interpretation scenarios. It can also be used for high-quality high-tech souvenirs to enrich the local cultural and creative industries and increase the added value of the local tourism economy.

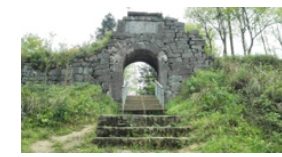

Figure 19. Real photograph of Erdao Gate, Hailongtun.

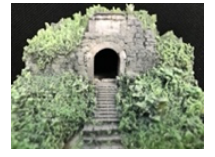

Figure 20. 3D printed model of Erdao Gate, Hailongtun.

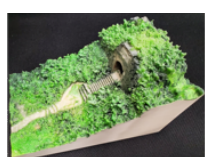

Figure 21. 3D printed model of Hailongtun Erdao Gate. 


\subsection{Building a panoramic presentation system based on 3D technology}

Due to the poor accessibility and the closure of Hailongtun during the COVID-19 pandemic, this study created a panoramic presentation system for the site based on 3D panoramic technology. Using panoramic spherical mapping technology, $360^{\circ}$ panoramic pictures were taken. Panoramic roaming was used to increase the good interaction between the audience and the application terminal. Virtual roaming combines two forms of operation - direct mouse click and a setting button-so the audience can rotate left and right and look up or look down during the roaming process; there is also a scene push and pull function to zoom in or out. In the roaming process, a smooth transition for switching between various scenic spots is realized. Presentation of the overall layout is combined with a floor plan to create the navigation, so the audience can quickly grasp the actual location of the observation point and the overall layout without getting lost. There is an interactive link between the navigation map and the 3D panorama, which combines navigation map guidance, picture presentation, text introduction, and a voice commentary to provide more information about the outstanding universal value of Hailongtun. The navigation setting allows the audience to switch quickly and conveniently between attractions of interest.

The Hailongtun panoramic navigation system used a DETUF4FD121 camera for capturing images. The camera was equipped with four all-glass fisheye lenses and a $190^{\circ}$ viewing angle, which ensured clear picture quality and reduced distortion. The F4 camera control application, which makes it possible to use a mobile phone to shoot remotely, made shooting and framing more flexible. Over seven days, more than 200 key points were selected within the 160.42 hectares of Hailongtun, and more than 2,000 on-site pictures were taken for later collage. The framing covered all of the important relics and roads in the core scenic area.

The DetuStitch software (which comes with the DETUF4FD121 camera) was used to complete the panorama collage. Image processing software was used to repair and unify the exposure and color in some of the pictures. In the end, 153 panoramic pictures reflecting the overall view of the core scenic area of Hailongtun were selected to establish a one-way roaming path from the Hailongtun Nianfangwan sightseeing car drop-off point to Toudao Gate. For each of the nine gates, a restoration model, archaeological site survey map, and speech and text commentary were added, and text and audio commentary about Hailongtun's outstanding universal value were added to important points and intersections. The audience can independently select the content of interest by clicking on the hotspot icon in the panorama (Figures 22). ${ }^{1}$

Navigation based on the plan of the core scenic area was created, so the audience could understand the location of the current panoramic view in real time and gain a more complete overall impression of the entire scenic area. At the same time, multiple scene switching modes such as hotspots, small pictures, and navigation were added to allow the audience to jump to a location in the virtual tour; this provides the audience with an immersive panoramic virtual tour experience.

${ }^{1}$ Available at:http://m.detu.com/zh/pano/show/691589?from=ti meline

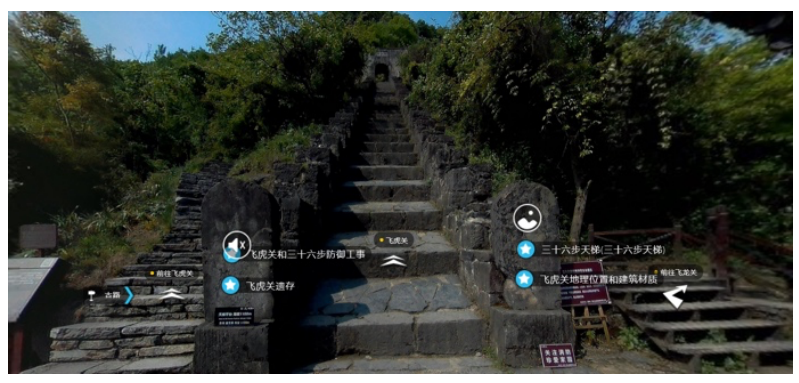

Figure 22. Panoramic presentation system for 36-step ladder.

\subsection{Restoration of damaged cultural relics based on digital carving technology}

The cultural relics unearthed within the heritage area are important evidence of outstanding universal value and are also a part of the sustainable development of the cultural heritage site. Most of these relics have been damaged, and it is complicated, time consuming, and labor intensive to repair them using traditional restoration techniques; there is also the risk that improper restoration may further damage the unearthed cultural relics. Digital restoration of cultural relics based on data may reduce labor costs, reduce the possibility of damage, and promote the sustainable development of the heritage site.

The archaeological excavations at Hailongtun have revealed some of the cultural relics that have been buried deep underground, but many are damaged or incomplete. Despite the efforts of modern archaeologist Qiaohui, they cannot be restored to their original, full appearance. This project explored the possibility of digitally repairing damaged artifacts using digital carving technology. The unearthed cultural relics were digitally scanned to build a 3D model; here, a damaged blue and white bowl is used as a case study. Using digital carving based on the symmetrical pattern of the artifact, a digital model was restored (Figures 23 and 24).

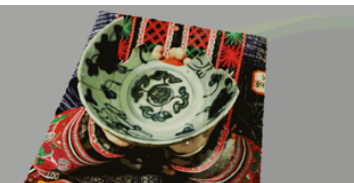

Figure 23. Bowl from Hailongtun based on point cloud model.

\subsection{Restoration of unearthed cultural relics based on 3D interpretation and presentation technology}

Important cultural artifacts unearthed at the site are not effectively kept there after archaeological excavation, so the archaeological team and the Provincial Museum have collected them. They are, however, officially listed in the collection, and it is difficult to bring them back to the heritage site for longterm preservation after being classified as important. The local heritage management agency has a strong desire to return the cultural relics, but this cannot be achieved in reality. Based on this situation, where the local site does not have the capacity to store or care for the relics, this research carried out a 3D digital scan of the collection, established and restored digital models, and then helped the heritage site to presentation the digital cultural relics. For a case study, this project carried out a nondestructive and non-contact digital scan of the Golden Phoenix 
Crown (with nine phoenixes and three dragons inlaid with precious stones, which was unearthed from the Tusi Tomb in the city of Zunyi, Guizhou Province) in the Guizhou Provincial Museum. Then 3D technology was used to digitally present these cultural relics (Figures 27-30). In the exhibition hall of the Guizhou Provincial Museum, pictures were taken at four angles, $30^{\circ}$ above, directly above, and $30^{\circ}$ below the Golden Phoenix Crown. A total of 1,400 photos were taken. Using the same 3D data processing software as above for digital splicing, the generated data were processed, and finally a replica of the Golden Phoenix Crown was created.
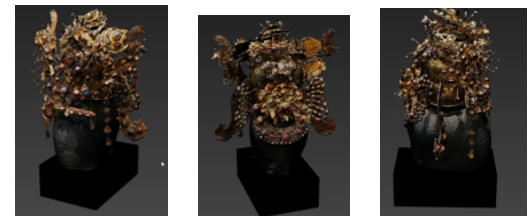

Figure 25-27. Digital restoration of the Golden Phoenix Crown from the Guizhou Provincial Museum after 3D digital scanning.

To increase the accuracy of the 3D data of cultural relics, this study also tried using 3D laser scanning technology to restore a high-precision and high-resolution digital model of jade ornaments found at the site. This technology can improve the accuracy, reliability, and efficiency of restoration; the system includes a 3D laser scanner, computer, power supply system, bracket, and system supporting software. Because 3D laser technology requires physical contact with the cultural relics, it was performed on an ungraded jade pendant and jade belt models at the suggestion of the museum. The main technical procedure was as follows: (1) the laser scanning equipment was assembled; (2) it was adjusted and tested, with a preliminary adjustment of the camera scanning range; (3) the equipment was calibrated, involving fine adjustment of the camera scanning range and scanning accuracy to ensure the accuracy of the scanned model; (4) the jade artifacts were scanned and a laser image model was generated; and (5) a digital model was generated (Figures 28).

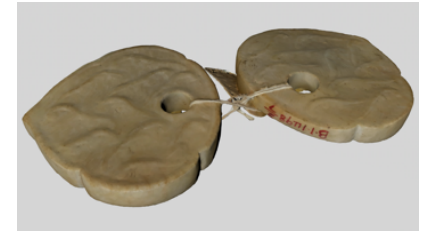

Figure 28. The jade pendant model from Hailongtun.

\subsection{Adding aerial photography presentation system with VR technology}

Because the architectural ruins of Hailongtun are on hills and the site is under heritage protection, there is no road to drive up the mountain. According to a survey of tourists to Hailongtun, it takes more than two hours to climb up to the site, which is very inconvenient for the elderly, children, and tourists with limited mobility. Although the site is still standing, because of its poor accessibility its value cannot be experienced by all tourists. Establishing a digital system that would allow tourists to experience the value of the world heritage intuitively and enhance their understanding even when they are not at the site is therefore necessary to promote its outstanding universal value. The impact of VR technology on cultural heritage is becoming increasingly significant. This research applied VR technology to demonstrate the outstanding universal value of the country's world cultural heritage(Wang, 2020). Wang (2020) reviewed a total of 409 literatures with the key words of "virtual reality technology + historic sites" and "virtual reality technology + cultural heritage" indexed in China National Knowledge Infrastructure, which published from January 2001 to May 1, 2019. The research notes that VR technology can be used to collect historical site data, establish a historical site model database, preserve historical site information resources, and presentation historical sites in $3 \mathrm{D}$, which can preserve historical sites for a long time. Guo and Fang (2008) supported that the use of virtual reality technology can collect historical data, establish historical model database, preserve historical information resources, and presentation historical sites in 3D, which can preserve historical sites for a long time. For Hailongtun, which is located in an economically underdeveloped area, VR technology can allow more tourists to learn about the site, as well as improve the effects of and opportunities for the exhibition of cultural relics.

In this project, the team used a DJI Yu drone equipped with an X360 panoramic camera to collect image data of the remains of the Hailongtun site and then performed panoramic editing of these image data to form an eight-minute VR file. This VR file introduces the universal value of Hailongtun, and, through the introduction of six of the gates, the site is fully demonstrated to be a material carrier of world cultural heritage. Those who engage with this VR experience will have a more accurate and profound understanding of the outstanding universal value of Hailongtun from the perspective of flying above the site.

Although some world cultural heritage sites have poor accessibility and a resulting low level of attention, they are still developing well. The present case of Hailongtun thus does not represent the problems faced by all world heritage sites, as other sites can often rely on unique resources and spectacular natural landscapes. They also often have a large amount of traditional and new media exposure, as well as a sound management system and stable economic support.

\subsection{Summary}

Although a single technical method has a certain reference significance for promoting the sustainable development of world heritage, the content of separate technical methods for the interpretation of the outstanding universal value of a site is not complete, and implementation of the technology remains weak. This study integrated six technical methods to form an overall heritage management program that allows different stakeholders to better understand the outstanding universal value of the site, which is an important way to promote its sustainable development. An outline of this overall program is presented in Table 1 .

Table 1: Six technical methods and their practical significance in promoting sustainable development

\begin{tabular}{|l|l|}
\hline Technical means & $\begin{array}{l}\text { Resolution of pain points for } \\
\text { sustainable development of poorly } \\
\text { accessible world heritage sites }\end{array}$ \\
\hline $\begin{array}{l}\text { Drone-based 3D } \\
\text { scanning and digital } \\
\text { recording }\end{array}$ & $\begin{array}{l}\text { 3D data of the heritage ontology can } \\
\text { be used for the heritage and ontology } \\
\text { digital records, so that stakeholders } \\
\text { who cannot enter the world heritage } \\
\text { can understand the outstanding } \\
\text { universal value of the world heritage }\end{array}$ \\
\hline $\begin{array}{l}\text { A 3D model of } \\
\text { reverse restoration }\end{array}$ & $\begin{array}{l}\text { The 3D model of the ruins of a gate at } \\
\text { Hailongtun can be used to }\end{array}$ \\
\hline
\end{tabular}




\begin{tabular}{|l|l|}
\hline $\begin{array}{l}\text { based on 3D } \\
\text { printing technology }\end{array}$ & $\begin{array}{l}\text { presentation the outstanding universal } \\
\text { value of the world heritage in 3D } \\
\text { images in different locations }\end{array}$ \\
\hline $\begin{array}{l}\text { Construction of a } \\
\text { panoramic } \\
\text { presentation system } \\
\text { for Hailongtun } \\
\text { based on 3D } \\
\text { panoramic } \\
\text { technology }\end{array}$ & $\begin{array}{l}\text { Allows stakeholders understand the } \\
\text { outstanding universal value of the } \\
\text { world heritage site via mobile and } \\
\text { online platforms }\end{array}$ \\
\hline $\begin{array}{l}\text { Digital restoration } \\
\text { of damaged cultural } \\
\text { relics based on } \\
\text { digital carving } \\
\text { technology }\end{array}$ & $\begin{array}{l}\text { Lets stakeholders understand the } \\
\text { outstanding universal value of the } \\
\text { heritage site through digital } \\
\text { restoration of cultural relics unearthed } \\
\text { in Hailongtun }\end{array}$ \\
\hline $\begin{array}{l}\text { Restoration of } \\
\text { unearthed cultural } \\
\text { relics based on 3D } \\
\text { interpretation and } \\
\text { presentation } \\
\text { technology }\end{array}$ & $\begin{array}{l}\text { Lets stakeholders learn about the } \\
\text { digital model of the cultural relics } \\
\text { unearthed in Hailongtun and make up } \\
\text { for the fact that the unearthed cultural } \\
\text { relics are part of the permanent } \\
\text { collection of the museum and cannot } \\
\text { be presentationed at the heritage site. }\end{array}$ \\
\hline $\begin{array}{l}\text { VR technology to } \\
\text { expand an aerial } \\
\text { photography } \\
\text { presentation system }\end{array}$ & $\begin{array}{l}\text { Aerial photography lets stakeholders } \\
\text { who cannot travel to the site } \\
\text { understand its outstanding universal } \\
\text { value }\end{array}$ \\
\hline
\end{tabular}

\section{CONCLUSION}

The crux of the problem of sustainable development for poorly accessible world cultural heritage lies in how to balance the protection and activation of the sites and increase the flow of tourists while also protecting the site. Heritage protection and activation have been the focus of technological breakthroughs, but the single technical means of heritage management tends to focus on an either/or approach: it is either limited to heritage protection, or limited to heritage interpretation and tourism promotion. This study proposed a sustainable heritage development approach that would integrate multiple digital methods, hoping to confront the problems faced by different world heritage sites with flexibility. The scientific problem is not how to use emerging interpretation technologies in heritage management, but how to use comprehensive technical methods to improve the interpretation and presentation of world cultural heritage objects despite poor site accessibility. Stakeholders interact and communicate to counteract poor accessibility, which is at the core of sustainable World Heritage development. The cost of such comprehensive technical means is very low and convenient for promotion, which gives this approach reference significance for other world cultural heritage sites facing poor accessibility.

\section{REFERENCES}

Auclair, E., \& Fairclough, G. (2015a). Living between past and future: An introduction to heritage and cultural sustainability. In Theory and practice in heritage and sustainability (pp. 1-22): Routledge.

Auclair, E., \& Fairclough, G. (2015b). Theory and practice in heritage and sustainability: Between past and future: Routledge. Barthel-Bouchier, D. (2016). Cultural heritage and the challenge of sustainability: Routledge.
Caserta, S., \& Russo, A. P. (2002). More means worse: Asymmetric information, spatial displacement and sustainable heritage tourism. Journal of Cultural Economics, 26(4), 245-260. Cassar, M. (2009). Sustainable heritage: Challenges and strategies for the twenty-first century, APT bulletin. Journal of Preservation Technology, 40(1), 3-11.

Cole, D. (2004). Exploring the sustainability of mining heritage tourism. Journal of Sustainable Tourism, 12(6), 480-494.

Gullino, P., Beccaro, G. L., \& Larcher, F. (2015). Assessing and monitoring the sustainability in rural world heritage sites. Sustainability, 7(10), 14186-14210.

Guo, Y., \& Fang, X. (2008). The effect of virtual reality on Chinese cultural relics. Art and Design: Theory(2), 118-120.

Howard, P., \& Pinder, D. (2003). Cultural heritage and sustainability in the coastal zone: experiences in south west England. Journal of Cultural Heritage, 4(1), 57-68.

Hribar, M. Š., Bole, D., \& Pipan, P. (2015). Sustainable heritage management: social, economic and other potentials of culture in local development. Procedia-Social and Behavioral Sciences, 188, 103-110.

Kosmas, P., Galanakis, G., Constantinou, V., Drossis, G., Christofi, M., Klironomos, I., . . . Stephanidis, C. (2020). Enhancing accessibility in cultural heritage environments: Considerations for social computing. Universal Access in the Information Society, 1-12.

Landorf, C. (2009). A framework for sustainable heritage management: A study of UK industrial heritage sites. International Journal of Heritage Studies, 15(6), 494-510.

Leff, E. (2012). Latin American environmental thinking: a heritage of knowledge for sustainability. Environmental ethics, 34(4), 431-450.

Li, Y., \& Hunter, C. (2015). Community involvement for sustainable heritage tourism: a conceptual model. Journal of Cultural Heritage Management and Sustainable Development.

Neumüller, M., Reichinger, A., Rist, F., \& Kern, C. (2014). 3D printing for cultural heritage: Preservation, accessibility, research and education. In 3D Research Challenges in Cultural Heritage (pp. 119-134): Springer.

Paladini, A., Dhanda, A., Reina Ortiz, M., Weigert, A., Nofal, E., Min, A., . . Santana Quintero, M. (2019). Impact of virtual reality experience on accessibility of cultural heritage. The International Archives of the Photogrammetry, Remote Sensing and Spatial Information Sciences, 42, 929-936.

Parrinello, S., \& Dell'Amico, A. (2019). Experience of Documentation for the Accessibility of Widespread Cultural Heritage. Heritage, 2(1), 1032-1044.

Partarakis, N., Klironomos, I., Antona, M., Margetis, G., Grammenos, D., \& Stephanidis, C. (2016). Accessibility of cultural heritage exhibits. Paper presented at the International Conference on Universal Access in Human-Computer Interaction.

Puyuelo Cazorla, M., Higón Calvet, J. L., Merino Sanjuan, L., \& Contero, M. (2013). Experiencing Augmented Reality as an Accessibility Resource in the UNESCO Heritage Site called" La Lonja", Valencia. Procedia Computer Science, 25, 171-178.

Ren, W., \& Han, F. (2018). Indicators for assessing the sustainability of built heritage attractions: An Anglo-Chinese Study. Sustainability, 10(7), 2504.

Silberman, N. A. (2007). Sustainable heritage? Public archaeological interpretation and the marketed past. Archaeology and Capitalism: From ethics to politics, 179-193.

Throsby, D. (2009). Tourism, heritage and cultural sustainability: three golden rules. Cultural tourism and sustainable local development, 17.

Wang, J. (2020). Literature review on the application of virtual reality technology in the study of historic sites. Media Forum, v.3;No.54(06), 145-146. 